\title{
A modeling study of seasonal variations of sea ice and plankton in the Bering and Chukchi Seas during 2007-2008
}

\author{
Jia Wang, ${ }^{1}$ Haoguo Hu, ${ }^{2}$ Joaquim Goes, ${ }^{3}$ Jennifer Miksis-Olds, ${ }^{4}$ Colleen Mouw, ${ }^{5}$ \\ Eurico D’Sa, ${ }^{6}$ Helga Gomes, ${ }^{3}$ D. R. Wang, ${ }^{7}$ Kohei Mizobata, ${ }^{8}$ Sei-ichi Saitoh, ${ }^{9}$ and \\ Lin $\mathrm{LuO}^{2}$
}

Received 28 June 2012; revised 11 December 2012; accepted 12 December 2012; published 28 March 2013.

[1] A nutrient $(\mathrm{N})$, phytoplankton (P), zooplankton (Z), and detritus (D) ecosystem model coupled to an ice-ocean model was applied to the Bering and Chukchi Seas for 2007-2008. The model reasonably reproduces the seasonal cycles of sea ice, phytoplankton, and zooplankton in the Bering-Chukchi Seas. The spatial variation of the phytoplankton bloom was predominantly controlled by the retreat of sea ice and the increased gradient of the water temperature from the south to the north. The model captures the basic structure of the measured nutrients and chl- $a$ along the Bering shelf during 4-23 July 2008, and along the Chukchi shelf during 5-12 August 2007. In summer 2008, the Green Belt bloom was not observed by either the satellite measurements or the model. The model-data comparison and analysis reveal the complexity of the lower trophic dynamics in the Bering and Chukchi Seas. The complexity is due to the nature that the physical and biological components interact at different manners in time and space, even in response to a same climate forcing, over the physically distinct geographic settings such as in the Bering and North Aleutian Slopes, deep Bering basins, Bering shelf, and Chukchi Sea. Sensitivity studies were conducted to reveal the underlying mechanisms (i.e., the bottom-up effects) of the Bering-Chukchi ecosystem in response to changes in light intensity, nutrient input from open boundaries, and air temperature. It was found that (1) a $10 \%$ increase in solar radiation or light intensity for the entire year has a small impact on the intensity and timing of the bloom in the physical-biological system since the light is not a limiting factor in the study region; (2) a $20 \%$ increase in nutrients from all the open boundaries results in an overall 7\% increase in phytoplankton, with the Slope region being the largest, and the Bering shelf and Chukchi being the smallest; and (3) an increase in air temperature by $2{ }^{\circ} \mathrm{C}$ over the entire calculation period can result in an overall increase in phytoplankton by $11 \%$.

Citation: Wang, J., et al. (2013), A modeling study of seasonal variations of sea ice and plankton in the Bering and Chukchi Seas during 2007-2008, J. Geophys. Res. Oceans, 118, 1520-1533, doi:10.1029/2012JC008322.

${ }^{1}$ NOAA Great Lakes Environmental Research Laboratory, Ann Arbor, Michigan, USA.

${ }^{2}$ Cooperative Institute for Limnology and Ecosystems Research (CILER), School of Natural Resources and Environment, University of Michigan, Ann Arbor, Michigan, USA.

${ }^{3}$ Lamont-Doherty Earth Observatory, Columbia University, New York, New York, USA.

${ }^{4}$ Applied Research Laboratory, Penn State University, University Park, Pennsylvania, USA.

${ }^{5}$ Michigan Technological University, Great Lakes Research Center Houghton, Michigan, USA.

${ }^{6}$ Department of Oceanography and Coastal Sciences, Louisiana State University, Baton Rouge, Louisiana, USA.

${ }^{7}$ Hainan Marine Development and Design Institute, Hainan, China.

${ }^{8}$ Tokyo University of Marine Science and Technology, Department of Ocean Sciences, 4-5-7, Kounan, Minato-ku, Tokyo, 108-8477, Japan.

${ }^{9}$ Graduate School of Fisheries Sciences, Hokkaido University, 3-1-1 Minato-cho, Hakodate, Hokkaido, Japan.

Corresponding author: J. Wang, NOAA Great Lakes Environmental Research Laboratory, Ann Arbor, Michigan, USA. (Jia.Wang@noa.gov)

(C)2012. American Geophysical Union. All Rights Reserved.

2169-9275/13/2012JC008322

\section{Introduction}

[2] The Bering Sea and the Gulf of Alaska have the most productive marine ecosystems in the world. The abundance of primary and secondary productivity is evidenced by large spring plankton blooms, abundance in benthic communities, and large populations of marine salmon, fish, birds, and mammals. This productivity makes up more than $10 \%$ of the worlds and about $52 \%$ of the U.S. seafood harvest [PMEL, 2000].

[3] The Bering Sea (Figure 1) is a complex, large semienclosed sea with an $\sim 500 \mathrm{~km}$ wide shallow shelf, a shelf break, and deep basins in which the ocean circulation systems are extremely dynamic (Figure 1). The deep water circulation includes (1) the Alaskan Stream (AS) along the Aleutian Peninsula, (2) the Bering Slope Current (BSC), (3) the Aleutian North Slope Current [ANSC; Stabeno et al., 1999], and (4) the Kamchatka Current (KC). The BSC splits into two coastal currents: the Anadyr Current (AC) and the southwestern coastal current, which forms the East $\mathrm{KC}$ (EKC). On the broad shallow shelf, there is a 


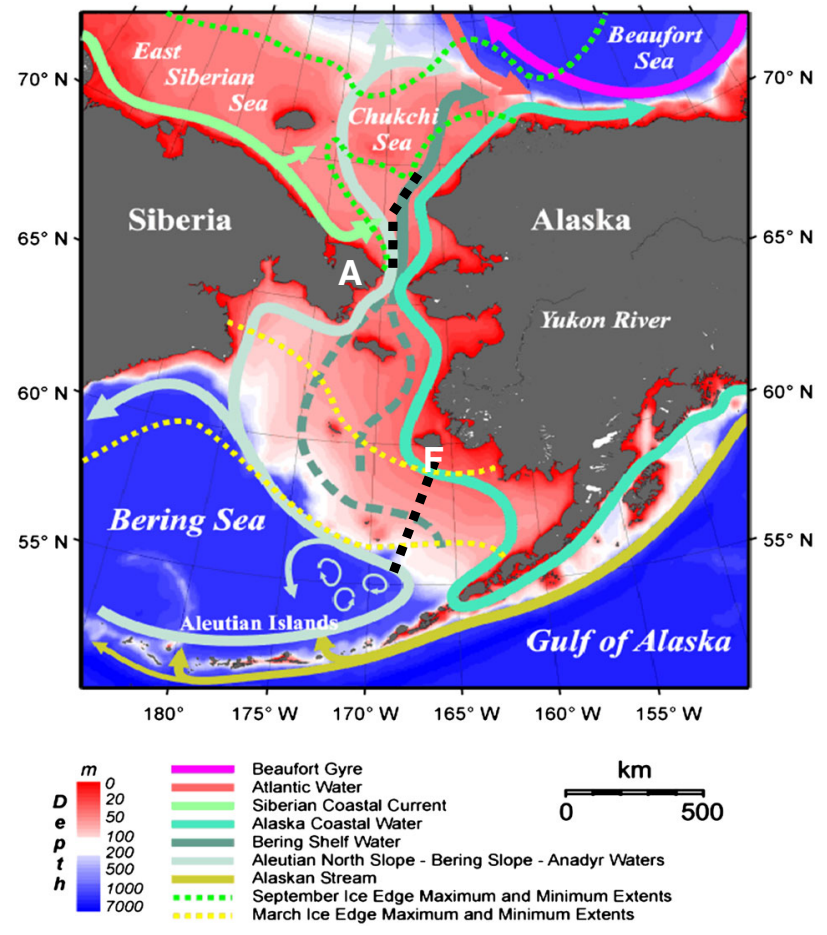

Figure 1. Topography and bathymetry of the Bering and Chukchi Seas, and the western/Pacific Arctic region. The schematic circulation systems are marked by colored arrows. Water depths are in meters (courtesy of T. Weingartner, University of Alaska Fairbanks; Danielson et al. [2011]). The model domain is from $50-74^{\circ} \mathrm{N}$ and $160^{\circ} \mathrm{E}-157^{\circ} \mathrm{W}$. Transects $\mathrm{A}$ and $\mathrm{F}$ are denoted by the dashed lines.

wide northwestward current following the topographic isobaths and the Alaskan Coastal Water/Current (ACC) on the Alaskan coast. Active mesoscale eddy genesis occurs along the AS and BSC due to the interaction between baroclinic instability and the sloping shelf break [Ikeda, 1983; Wang and Ikeda, 1997; Mizobata et al., 2002, 2006, 2008; Maslowski et al., 2008]. The water exchange between shelf and deep basin waters is due to a mesoscale eddy motion that contributes to abundance in biomass along the Green Belt [Springer et al., 1996; Okkonen et al., 2004; Mizobata et al., 2006]. The water exchange between the AS and the Bering deep basins due to mesoscale eddies also contributes to the ocean circulation inside the Bering Sea [Clement Kinney et al., 2013].

[4] An extensive review of early hydrographic measurements, as well as ice and ocean circulation modeling, is given in Wang et al. [2009a]. Early systematic studies on ecosystem dynamics related to physical forcing were conducted on the Bering and Chukchi shelves as part of the Inner Shelf Transfer and cycling in the Bering-Chukchi Seas project [Coachman and Handell, 1993]. However, this project did not include the interactions between the shelf ecosystem and the deep basins. Springer et al. [1996] reviewed the Bering Sea shelfedge processes and ecosystem productivity, referred to as the "Green Belt," and the high productivity near the shelf break (i.e., along the BSC) was qualitatively described. Some hypotheses have suggested the linkage of primary productivity to climate warming [Overland and Stabeno, 2004; Grebmeier et al., 2010], shelf-basin exchanges, upwelling, and nutrient pumping associated with mesoscale eddy activity. Utilizing satellite and in situ measurements and idealized models, Mizobata et al. [2006, 2008] examined the linkage between the high productivity along the Green Belt and mesoscale eddy-induced nutrient pumping, which maintains the prolonged summer blooms. However, these hypotheses need to be tested using both observations and sophisticated ice-ocean models in realistic settings.

[5] In the Bering and Chukchi seas, sea-ice cover is an important predictor of regional climate [Niebauer, 1980; Wang and Ikeda, 2001]. Sea-ice extent also influences ocean circulation patterns, horizontal and vertical thermal structures, plankton dynamics [Mizobata et al., 2011], and ecosystem functioning. Eslinger and Iverson [2001] developed a 1-D biological model and applied it to the Bering Sea, Prince William Sound, and the Gulf of Alaska [Eslinger et al., 2001]. Wang et al. [2003a] extended Eslinger's 1-D biological model to a generalized 3-D model which was coupled to the Princeton Ocean Model (POM) and is referred to as the Physical-Ecosystem Model (PhEcoM). Using a 1-D version of PhEcoM, Jin et al. [2006a] studied plankton blooms at a mooring site (M2 site: $56.9^{\circ} \mathrm{N}, 164.1^{\circ} \mathrm{W}$ ) on the southeastern Bering shelf. Furthermore, the 1-D model was implemented with a four-compartment ice algae model that was applied to the Chukchi Sea landfast ice region [Jin et al., 2006b] and M2 site [Jin et al., 2007]. Additionally, the interannual variability of ice-covered ice algae and plankton blooms was investigated for the M2 site for the period 1995-2005 [Jin et al., 2009]. It was found that climate change, through its effect on the timing and the rate of ice melting, influences the timing and magnitude of phytoplankton and zooplankton blooms, because sea-ice conditions [Wang et al., 2009a; Zhang et al., 2010a] and the ecosystem [Grebmeier et al., $2010]$ in the Bering and Chukchi seas are driven mainly by atmospheric forcing, from tidal, synoptic, and seasonal, to interannual and decadal time scales.

[6] During the International Polar Year (IPY) from 2007 to 2009, extensive multidisciplinary field campaigns were conducted by multiple nations, particularly by the Pacific Arctic Group. An all time low Arctic September sea-ice extent occurred in 2007 [Wang et al., 2009b; Zhang et al., 2008, and many others] due to the positive Arctic Dipole Anomaly (DA)-related wind anomaly [Wu et al., 2004, 2006; Watanabe et al., 2006]. Since then, the Arctic summer sea ice has remained low from 2007 to 2012 with a new record low occurring in September 2012 [Wang et al., 2013]. The major region impacted by the positive DA was the western Pacific Arctic including the Chukchi, Beaufort, and East Siberian Seas. The western Pacific Arctic ecosystem was profoundly impacted by the record low sea-ice cover [Zhang et al., 2010b; Jin et al., 2011; Deal et al., 2013]. Nevertheless, the Bering Sea experienced severe winter ice cover (or lower air and water temperature) from 2006 to 2009 [Overland et al., 2013; Wang et al., 2013], which is opposite of the Arctic summer sea-ice coverage and indicates that the Bering Sea system is mainly driven by atmospheric forcing and due to a small thermal memory of the past winter. Nevertheless, in addition to atmospheric forcing, the Arctic Ocean is also controlled by heat transport from the northern Atlantic Ocean and from the northern Pacific via the Bering Strait, and the thermal memory (or inertia) is an important process of the Arctic climate system, relating to ice/ocean albedo feedback 
[Wang et al., 2005a; Wang et al., 2013]. The distinction between the shallow northern Bering-southern Chukchi Seas and the Arctic Ocean should be considered in ecosystem modeling studies.

[7] During the IPY and beyond, extensive observational [Brown et al., 2011] and coupled ice-ocean modeling studies were conducted to reveal the response of the Bering Sea iceocean system to changing climate [Wang et al., 2009a; Clement Kinney et al., 2009; Hu and Wang, 2010; Zhang et al., 2010a; Ezer and Oey, 2010]. Although some modeling studies of Arctic ecosystems were conducted [Zhang et al., 2010b; Jin et al., 2011], similar studies in the Bering and Chukchi Seas have been limited by the complexity of the ecosystem dynamics.

[8] This study builds upon previous accomplishments of applying the 1-D version of the PhEcoM and couples a 3-D NPZD ecosystem model to the 3-D Coupled Ice-Ocean Model (CIOM) [Wang et al., 2002; 2009a; Hu and Wang, 2010; Hu et al., 2011]. The coupled model was implemented for the Bering and Chukchi Seas during 2007-2008. The simulation period was chosen to allow for overlap with IPY ship measurements which were used to validate the model results, to reveal key ecosystem features measured during the IPY field campaign in the Bering-Chukchi Seas, and to examine the underlying mechanisms of the physical-biological interactions and their response to a changing climate and nutrient input.

[9] This paper is organized as follows. In the next section, the CIOM and PhEcoM will be briefly introduced. Modeling results will be discussed in section 3 , in conjunction with the field measurements. Sensitivity studies and discussion are given in section 4 , followed by summary and conclusions in section 5 .

\section{Model Description, Configuration, Forcing, and Measurement Data}

\subsection{CIOM}

[10] The detailed description of the CIOM development can be found in Yao et al. [2000] and Wang et al. [2002, $2005 \mathrm{~b}$. The CIOM has been successfully applied to the Labrador Sea [Yao et al., 2000; Tang, 2008], the pan-Arctic Ocean [Wang et al., 2004 2005b; Wu et al., 2004; Long et al., 2012], the Beaufort Sea [Wang et al., 2003b, 2008], and the Bering Sea [Wang et al., 2009a; Hu and Wang, 2010; Hu et al., 2011]. The ocean model used is the POM [Blumberg and Mellor, 1987; Mellor, 2004], and the ice model used is a full thermodynamic and dynamics model [Hibler, 1979, 1980] that prognostically simulates sea-ice thickness, sea-ice concentration, ice edge, ice velocity, and heat and salt flux through sea ice into the ocean. The ice model has full thermodynamics with one-layer ice and full dynamics with viscous-plastic rheology [Hibler, 1979, 1980; Wang et al., 1994]. A multiple thickness category ice model [Throndike et al., 1975; Hibler, 1980] was used, fully coupled to the ocean model [Mellor and Kantha, 1989]. The prognostic and diagnostic variables include ice velocity, compactness (concentration), ice edge, and thickness. In this study, 10 ice categories $(0.0,0.2,0.4,0.8,1.6$, $3.2,4.8,5.4,7.0$, and $12.6 \mathrm{~m})$ were used, each consisting of a percentage in a grid point. The summation of each category thickness is the mean thickness at each grid. Thus, sea-ice concentration at each grid is solved.

\subsection{PhEcoM}

[11] The PhEcoM was developed by Wang et al. [2003a] in a flexible 3-D manner similar to POM and was fully coupled to POM. The 1-D version has been applied to the Bering and Chukchi Seas with an ice algae submodel [Jin et al., 2006a, 2006b, 2007, 2009]. A 3-D version was also applied to the Bohai Sea [Wang et al., 2003a] and the Yellow Sea [Hu et al., 2004]. This study is the first time the 3-D PhEcoM is applied to the Bering and Chukchi Seas. A flow chart of the four-compartment ecosystem dynamics is shown in Figure 2. The biological model includes three nutrients $\left[\mathrm{N}\right.$ : nitrate $\left(\mathrm{NO}_{3}\right)$, phosphate $\left(\mathrm{PO}_{4}\right)$, and silicate $\left(\mathrm{SiO}_{3}\right)$ ], phytoplankton $(\mathrm{P})$, zooplankton $(\mathrm{Z})$, and detritus (D). The basic biological partial differential equations are described as below.

$$
\begin{aligned}
& \left(\frac{\mathrm{d}}{\mathrm{dt}}-\nabla^{2}\right) \cdot P=\text { Grow } \cdot P-m_{\mathrm{p}} \mathrm{e}^{\mu_{p} \mathrm{~T}} \cdot P-d_{\mathrm{p}} \cdot P-g_{\mathrm{z}} \cdot P \cdot \mathrm{e}^{\mu_{\mathrm{z}} \mathrm{T}} \\
& \left(\frac{\mathrm{d}}{\mathrm{dt}}-\nabla^{2}\right) \cdot Z=\beta g_{\mathrm{z}} \mathrm{Pe}^{\mu_{z} T}\left(1-\mathrm{e}^{-\lambda P}\right) \cdot Z \\
& \left(\frac{\mathrm{d}}{\mathrm{dt}}-\nabla^{2}\right) \cdot N=- \text { Grow } \cdot P+m_{p} e^{\mu_{p} T} \cdot P+m_{z} \cdot Z+\varepsilon \cdot D \\
& \left(\frac{\mathrm{d}}{\mathrm{dt}}-\nabla^{2}+W_{s} \frac{\partial}{\partial z}\right) \cdot D=-d_{\mathrm{z}} \cdot P+d_{\mathrm{z}} \cdot Z \\
& \quad+(1-\beta) g_{\mathrm{z}} \mathrm{Pe}^{\mu_{z} T}\left(1-\mathrm{e}^{\lambda P}\right) \cdot Z-\varepsilon \cdot D
\end{aligned}
$$

[12] Equation (3) is for nutrients including $\mathrm{NO}_{3}, \mathrm{PO}_{4}$, and $\mathrm{SiO}_{3}$, which use the same equation, but with different coefficients (Table 1) for uptake and release. The total/substantial derivative/operator

$$
\frac{\mathrm{d}}{\mathrm{dt}}=\frac{\partial}{\partial t}+u \frac{\partial}{\partial x}+v \frac{\partial}{\partial y}+w \frac{\partial}{\partial z},
$$

is defined as the time and local (advection) changes, and the operator

$$
\nabla^{2}=\frac{\partial}{\partial x}\left(K_{H} \frac{\partial}{\partial x}\right)+u \frac{\partial}{\partial y}\left(K_{H} \frac{\partial}{\partial y}\right)+\frac{\partial}{\partial z}\left(K_{\mathrm{V}} \frac{\partial}{\partial z}\right)
$$

is the horizontal and vertical diffusivity, where $u$ and $v$ are the water velocity; $K_{H}$ and $K_{V}$ are the horizontal and vertical diffusivity coefficients, respectively, which are passed from the CIOM based on the Smagrinsky formulation for $K_{V H}$, and based on the Mellor-Yamada 2.5 turbulence closure

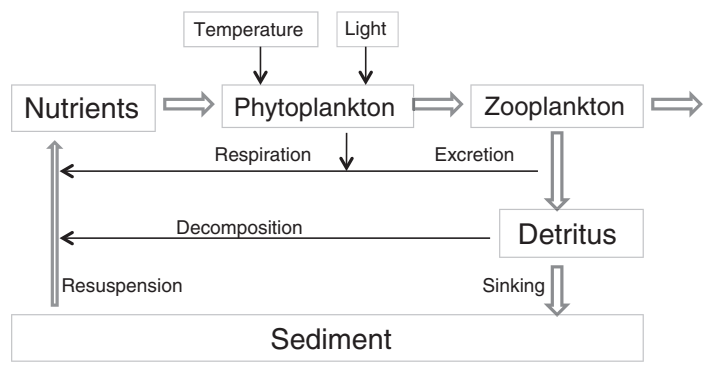

Figure 2. Schematic flow chart of the six-compartment ecosystem model. 
Table 1. Parameters Used in This Version of PhEcoM

\begin{tabular}{|c|c|c|c|}
\hline Para & Description & Value Unit & Reference \\
\hline$g_{p}$ & Maximum phytoplankton growth rate & $0.03 \mathrm{~h}^{-1}$ & Eppley $[1972]$ \\
\hline$\mu_{p}$ & Exponent coefficient related to temperature & $0.0633^{\circ} \mathrm{C}^{-1}$ & Eppley [1972] \\
\hline$m_{p}$ & Maximum phytoplankton respiration rate & $0.005 \mathrm{~h}^{-1}$ & This study \\
\hline$d_{p}$ & Phytoplankton mortality rate & $0.0075 \mathrm{~h}^{-1}$ & This study \\
\hline$\gamma_{1}$ & Light limitation coefficient 1 & $0.0536 \mathrm{~m}^{2} / \mathrm{W}$ & Platt [1980] \\
\hline$\gamma_{2}$ & Light limitation coefficient 2 & $0.001795 \mathrm{~m}^{2} / \mathrm{W}$ & Platt [1980] \\
\hline$\lambda$ & Phytoplankton attenuation rate & $1.5 \mathrm{~m}^{3} / \mathrm{mg}$ & Ivlev [1945] \\
\hline$g_{z}$ & Maximum zooplankton growth rate & $0.025 \mathrm{~h}^{-1}$ & Ivlev [1945] \\
\hline$\mu_{z}$ & Exponent coefficient related to temperature & $0.06^{\circ} \mathrm{C}^{-1}$ & Ivlev [1945] \\
\hline$m_{\mathrm{z}}$ & Maximum zooplankton excretion & $0.006 \mathrm{~h}^{-1}$ & This study \\
\hline$d_{\mathrm{z}}$ & Zooplankton mortality rate & $0.0015 \mathrm{~h}^{-1}$ & This study \\
\hline$\beta$ & Zooplankton growth efficiency & 0.75 & Oguz [1996] \\
\hline$k_{S i}$ & Half-saturation constant for silicate & $4.0 \mathrm{mmol} / \mathrm{m}^{3}$ & This study \\
\hline$k_{N}$ & Half-saturation constant for nitrogen & $3.0 \mathrm{mmol} / \mathrm{m}^{3}$ & This study \\
\hline$k_{P}$ & Half-saturation constant for phosphate & $0.3 \mathrm{mmol} / \mathrm{m}^{3}$ & This study \\
\hline$\varepsilon$ & Detritus remineralization rate & $0.004 \mathrm{~h}^{-1}$ & This study \\
\hline$W_{s}$ & Detritus sinking velocity & $3.0 \mathrm{~m} / \mathrm{s}$ & This study \\
\hline$C_{1}$ & Nitrogen in per unit chlorophyll a & $0.3 \mathrm{mmolN} / \mathrm{mgChla}$ & This study \\
\hline
\end{tabular}

model for $K_{V}$. Furthermore, the following surface windwave mixing parameterization of $H u$ and Wang [2010] $K_{m w}=\frac{2 v^{2}}{g} \delta \beta^{3} W^{3} e^{\frac{g z}{\beta^{2} W^{2}}}$ was added to $K_{V}$ to enhance the vertical mixing in the upper ocean, where $K_{m w}$ is the waveinduced mixing coefficient; $\beta$ is the wave age $(0<\beta<1$ for growing waves, and $\beta=1$ for mature waves), $\delta$ is the wave steepness $(\delta=2 \alpha / \lambda, \alpha$ is the amplitude and $\lambda$ is the wavelength), $W$ is the wind speed, $z<0$ is the depth, $v=0.4$ is the von Kármán constant, and $g$ is acceleration of gravity. In this study, a mature but not breaking wave is assumed as $\beta=0.4, \delta=0.16$. The vertical diffusivity coefficient $K_{m w}$ for temperature, salinity, and ecological variables is assumed to be equal to the eddy diffusivity $K_{m w}$.

[13] Phytoplankton growth rate is defined as

$$
\text { Grow } \cdot P=g_{p} \mathrm{e}^{\mu_{p} T} \cdot \min \left[f_{\mathrm{n}}, \mathrm{e}^{-\gamma_{1} I}\left(1-\mathrm{e}^{-\gamma_{2} I}\right)\right] \cdot P
$$

where the nutrient limitation function is

$$
f_{n}=\min \left(\frac{N}{N+k_{N}}, \frac{P}{P+k_{P}}, \frac{S i}{S i+k_{S i}}\right)
$$

where $k_{N}, k_{P}, k_{S i}$ are the half-saturation constants of nitrogen, $\mathrm{PO}_{4}$, and $\mathrm{SiO}_{3}$ (see Table 1), respectively. The ratios are given as $\mathrm{P}: \mathrm{N}: \mathrm{Si}=1: 15: 20$.

$$
\left(1-e^{-r_{1} I}\right) e^{-r^{2} I}
$$

is the light limitation function, in which $I=I_{0} e^{-k z}, I_{0}$ is the sea surface light intensity, $k$ is the light attenuation coefficient, and $z$ is the water depth.

$$
m_{\mathrm{p}} \mathrm{e}^{\mu_{p} T} \cdot P
$$

is the phytoplankton respiration function. Zooplankton feeding on phytoplankton is given by

$$
g_{\mathrm{z}} \cdot P \cdot \mathrm{e}^{\mu_{z} T}\left(1-\mathrm{e}^{\lambda P}\right) \cdot Z
$$

and

$$
W_{s} \frac{\partial D}{\partial z}
$$

is the detritus sinking function, where $W_{s}$ is the sinking velocity. The values of the parameters are listed in Table 1.

\subsection{Model Configuration and Forcing}

[14] The CIOM was configured in horizontal spherical grids with $1 / 6^{\circ}$ longitudes $(\sim 5.0 \mathrm{~km}$ in the northern boundary and $\sim 10 \mathrm{~km}$ near the Aleutian Islands) and $1 / 12^{\circ}$ latitudes $(\sim 9.2 \mathrm{~km})$ covering the whole Bering Sea and southern Chukchi Sea. There are 24 sigma levels for the ocean model in the vertical (at $\sigma=0,-0.008,-0.016,-0.031,-0.063$, $-0.125,-0.188,-0.250,-0.313,-0.375,-0.438$, $-0.500,-0.563,-0.625,-0.688,-0.750,-0.813$, $-0.875,-0.938,-0.969,-0.984,-0.992,-0.996$, and -1 ; here $\sigma=\frac{z-\eta}{H+\eta}$ where $z$ is vertical coordinate and negative downward, $\eta$ is the mean water elevation, and $H$ is the water depth). The vertical resolution is higher near the surface and the bottom for a better representation of the surface and bottom boundary layers. The open boundaries (velocity, temperature, and salinity) are embedded by a global climate (atmosphere-ice-ocean-land) model with a resolution of $1 / 6 \times 1 / 4^{\circ}$ [about $25 \mathrm{~km}$; Watanabe et al., 2006].

[15] The model was initialized with climatologic temperature and salinity data from the Polar Science Center Hydrographic Climatology [PHC 3.0, Steele et al., 2001]. National Centers for Environmental Prediction (NCEP) 6 hourly reanalysis data consisting of wind, air temperature, shortwave radiation, precipitation, humidity, and sea level pressure were used to drive the model. The NCEP reanalysis datasets are created by assimilating climate observations into a climate model throughout the entire reanalysis period in order to obtain observation-constrained model results. Observations are from many different data sources including ship, satellite, ground station, radiosonde observation, and radar measurements. The NCEP reanalysis products are widely used by the community. The sea-ice velocity, concentration, and thickness were set to zero as initial conditions. After a 4 year spinup utilizing the 2006 forcing, a dynamic and thermodynamic seasonal cycle was established. The model was then run for years 2007-2008 with 6 hourly atmospheric forcing using the previous fourth-year output as the initial conditions.

[16] The initial conditions for nutrients were derived from the World Ocean Database 2009, which archives the digitized annually mean $\mathrm{NO}_{3}, \mathrm{PO}_{4}$, and $\mathrm{SiO}_{3}$ in a grid format of $2 \times 2^{\circ}$ at standard depths. Seasonal surface chl- $a$ concentration data were used, and there were no usable zooplankton 
data. These annually averaged data were interpolated into the model grids in both horizontal and vertical directions. Along the lateral open boundaries, the same annual mean data were used to prescribe the boundary forcing to the $\mathrm{PhEcoM}$ with no seasonal and interannual variability.

[17] Based on the global linear stability criteria proposed by Wang [1996], the minimum depth was set to $10 \mathrm{~m}$ according to the stability condition, $h_{\min }+\zeta_{\max }>0$, where $h_{\min }$ is the minimum water depth, and $\zeta_{\max }$ is the maximum water elevation possibly caused by strong (gust) winds and storm surges along the coast. Based on the CFL criterion, one of the global stability conditions, the internal mode time step of the numerical integration is $600 \mathrm{~s}$, while the external mode time step is $20 \mathrm{~s}$. The time step for the NPZD model is also $600 \mathrm{~s}$, while the source and sink terms of the NPZD model are updated every 30 min.

\subsection{Satellite and In Situ Measurements}

[18] Satellite measurements of chlorophyll concentration from the Sea-viewing Wide Field-of-view Sensor (SeaWiFS) were obtained from the NASA Ocean Biology Processing Group's data archive (http://oceandata.sci.gsfc.nasa.gov/) at Goddard Space Flight Center. The standard local area coverage $(1 \mathrm{~km})$ chlorophyll product was utilized. The standard algorithm is a band-ratio approach [O'Reilly et al., 1998] which is known to overestimate chlorophyll concentration when the contribution of colored dissolved organic matter (CDOM) is high, which is the case for the Bering and Chukchi Seas (P. Naik et al., Light absorption properties in southeastern Bering Sea during July 2008: analysis, parameterization and absorption budget, submitted to Remote Sensing of Environment, 2013). The standard chlorophyll product was used in this study as a relative measure of spatial variability, not an absolute concentration for quantitative comparisons.

[19] In situ measurements from two IPY cruises, one in each of the Bering and Chukchi Seas were used to compare with the model results. The Bering Sea cruise on the southeastern Bering shelf that occurred 4-23 July 2008 (depicted as transect F, Figure 1) was part of a Bering Sea Ecosystem Study cruise on the US coast guard vessel Healy. The Chukchi Sea cruise (depicted as transect A, Figure 1) occurred on Hokkaido University's vessel Oshoro-Maru on the southern Chukchi Sea during 5-12 August 2007 (see Figure 1 for the locations of the transects). The shipboard data (water samples for nutrients and conductivity) was measured using a salinometer calibrated with standard seawater.

\section{Results}

\subsection{Ocean Circulation and Sea-ice Variation}

[20] The average surface ocean circulation of the upper $20 \mathrm{~m}$ was mainly driven by surface wind throughout the annual cycle. In July 2008, weak southwesterly winds dominate over the Bering Sea. Therefore, the surface current (Figure 3a) on the shelf was dominated by the southeastward Ekman drift [Wang et al., 2009a; Hu and Wang, 2010]; even above the BSC, the surface current flowed in the opposite direction to the BSC. The BSC is weak at the surface because the Ekman drift was just opposite to the BSC. There were numerous mesoscale eddies in the deep Bering Sea basins, with anticyclonic eddies outnumbering cyclonic eddies. The eddy occurrence was consistent with measurements
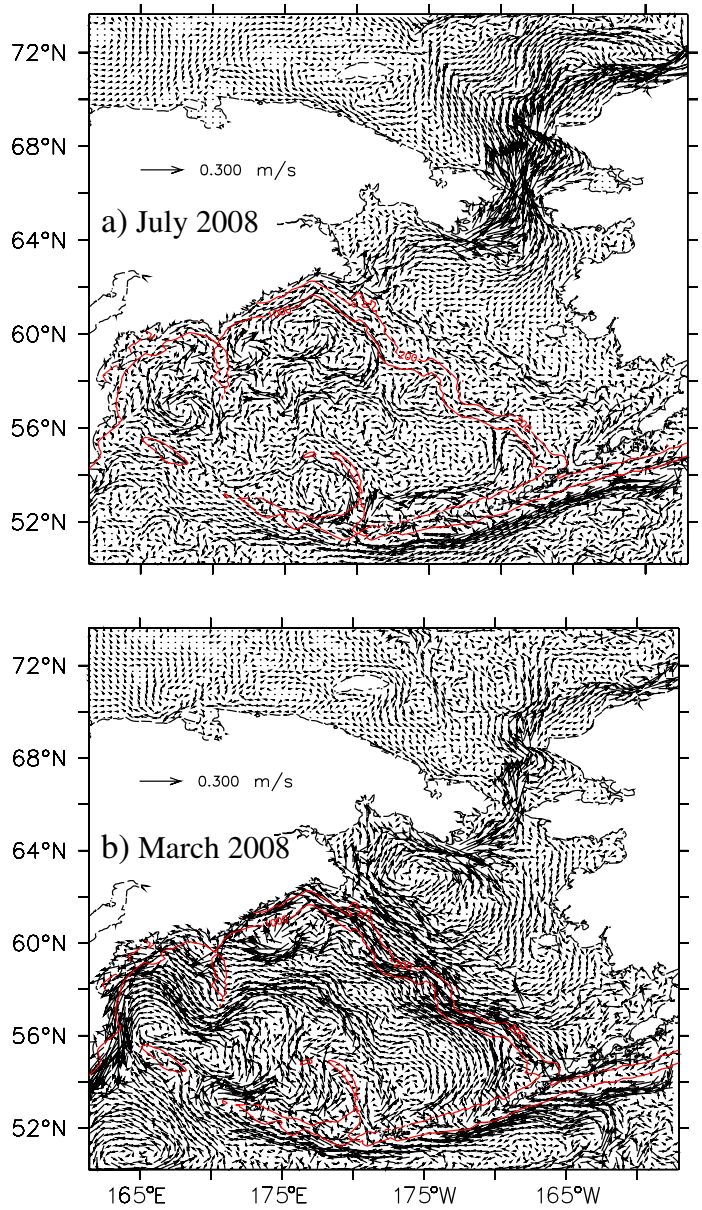

Figure 3. Modeled upper $20 \mathrm{~m}$ average ocean circulation in (a) March and (b) July 2008.

[Mizobata et al., 2002, 2006; Mizobata and Saitoh, 2004] and theoretical analysis [Wang and Ikeda, 1997]. Wang and Ikeda [1997] found that the negative sloping shelf breaks, such as along the BSC, the AS, and the Labrador Current [Griffiths et al., 2000], promote shorter mesoscale waves (eddies) and more anticyclones than cyclones, while the positive sloping shelf breaks such as along the Kuroshio and the Gulf Stream dampen the short waves (eddies) and promote long waves and meanderings.

[21] Along the Siberian coast, the AC was intensified in summer due to both wind forcing and the Pacific-Arctic pressure head. These forcings, working together in the same direction, enhance the Bering Strait outflow, which produced a year-round northward transport of $\sim 0.8 \mathrm{~Sv}$ [Woodgate et al., 2005]. During the winter (Figure 3b), the weaker Bering Strait outflow is due to the opposition between the Pacific-Arctic pressure head and northerly winds. In the southern Chukchi Sea, besides the East Siberian Current (ESC) that flowed southeastward along the Arctic Siberian coast, there were three obvious branches: the ACC, the Central Channel Branch, and the Herald Canyon Branch, consistent with the measurements [Woodgate et al., 2005] and idealized model results [Spall, 2007].

[22] In winter (Figure 3b), the prevailing northwestward surface Ekman current on the shelf and deep basins was mainly driven by northerly winds. Strong wind-driven 
circulation homogenized the vertical shear of the BSC and EKC by strong mixing and weakening baroclinic instability, leading to fewer mesoscale eddies in the deep basins (Figure 3b), compared to the summer (Figure 3a). Since the northerly wind-driven current was against the northward current driven by the Pacific-Arctic pressure head, the AC and the Bering Strait outflow were weaker in winter than in summer. As a result, all three branches in the southern Chukchi Sea weakened; in particular, the ACC and the Herald Canyon Branch.

[23] To calibrate model performance, the observed Bering Strait outflow [Woodgate and Aagaard, 2005] was compared to the model results. Figure 4 shows the simulated and measured time series of Bering Strait outflow during 2007-2008. The daily model-data comparison shows that although the model mean transport $\left(0.75 \mathrm{~Sv} ; 1 \mathrm{~Sv}=10^{6} \mathrm{~m}^{3} \mathrm{~s}^{-1}\right)$ is close to the measured transport $(0.77 \mathrm{~Sv})$,the model also tends to produce a smoother value. The observed transport has a larger standard deviation $(0.77 \pm 0.97 \mathrm{~Sv})$ than the modeled transport $(0.75 \pm 0.76 \mathrm{~Sv})$, indicating large variability of the outflow. The simulated maximum/minimum (northward/ southward or reverse flow) transport was $2.40 /-1.75 \mathrm{~Sv}$, respectively, which is smaller than the measurements of $3.58 /-2.60 \mathrm{~Sv}$. Figure $4 \mathrm{~b}$ shows the 30 day moving average transport. The correlation between the modeled and measured time series is 0.76 with a root mean square deviation (a measure of variation from the mean) of $38 \%$, and a mean absolute deviation (a measure of average error) of $29 \%$. The other statistics are also given in Figure 4.

[24] The CIOM-simulated sea-ice thickness of March 2008 is shown in Figure 5, with the satellite-measured seaice edge during the same period. Since the 2007 winter was a negative $\mathrm{AO}$ year, and because the positive DA year persisted from winter to summer [Wang et al., 2009b], the

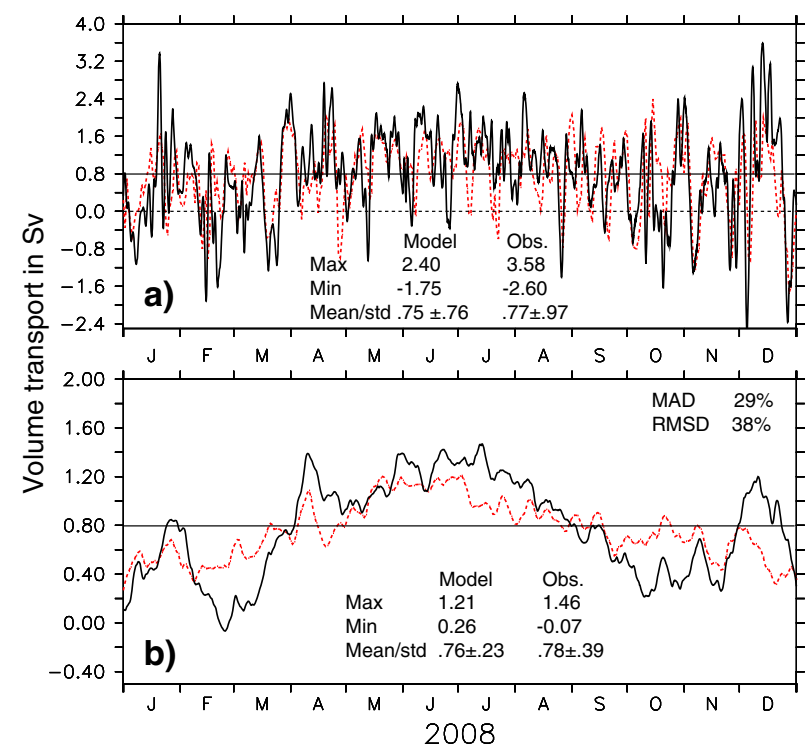

Figure 4. Comparison of simulated (dashed/red lines) and measured (solid/black lines) Bering Strait transport in Sverdrup $\left(1 \mathrm{~Sv}=10^{6} \mathrm{~m}^{3} \mathrm{~s}^{-1}\right)$ in 2008 . (a) Daily model output vs daily measurements and (b) 30 day moving average for both model output and measurements. The simulated transport statistics are given.

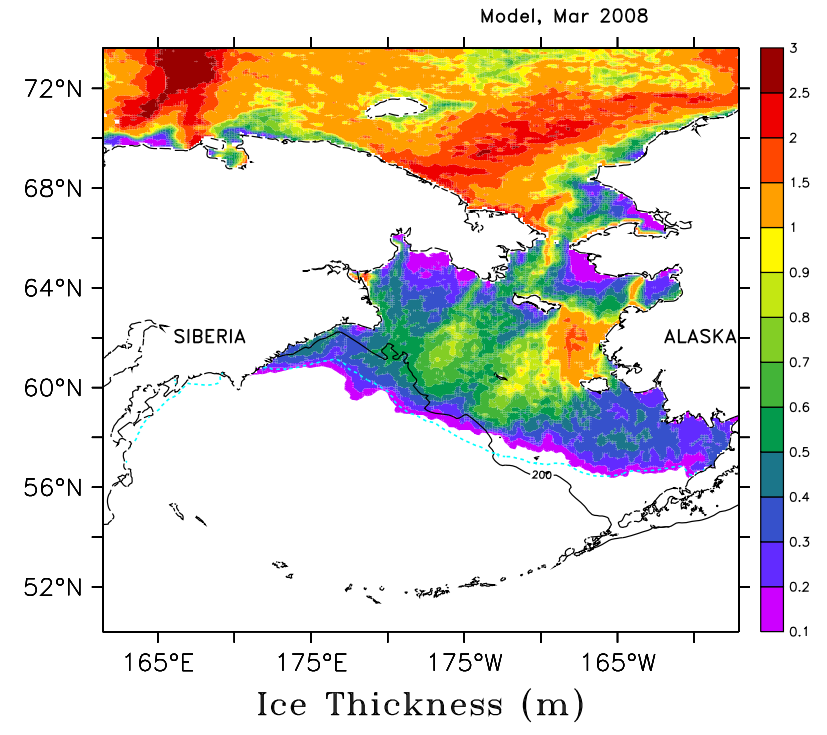

Figure 5. Modeled sea-ice thickness (in meters) and satellitemeasured sea-ice edge (green dashed line) in March 2008. The $200 \mathrm{~m}$ isobath is noted as a solid black line.

DA-derived wind anomaly was dominated by southerly winds, advecting the warm air from the Bering Sea to the Pacific Arctic Ocean (Chukchi, East Siberian, and Beaufort Seas) and advecting excessive anomalously warm Bering Sea water into the Chukchi Sea [Wang et al., 2009b; Mizobata et al., 2010; Woodgate et al., 2010], causing earlier melting. Figure 5 shows that in March 2008, there was thin ice along the Alaskan coast from the northern Bering Sea to the southern Chukchi Sea, and along the Siberian coast in the Bering Sea, indicating early melting due to strong advection of southerly winds. Although the ice edge in March of 2008 covered the entire shelf, the ice thickness was thin compared to the climatological mean ice thickness of $0.8-1 \mathrm{~m}$. This indicates that the 2008 winter experienced early melting in the Chukchi Sea as well as in the northern

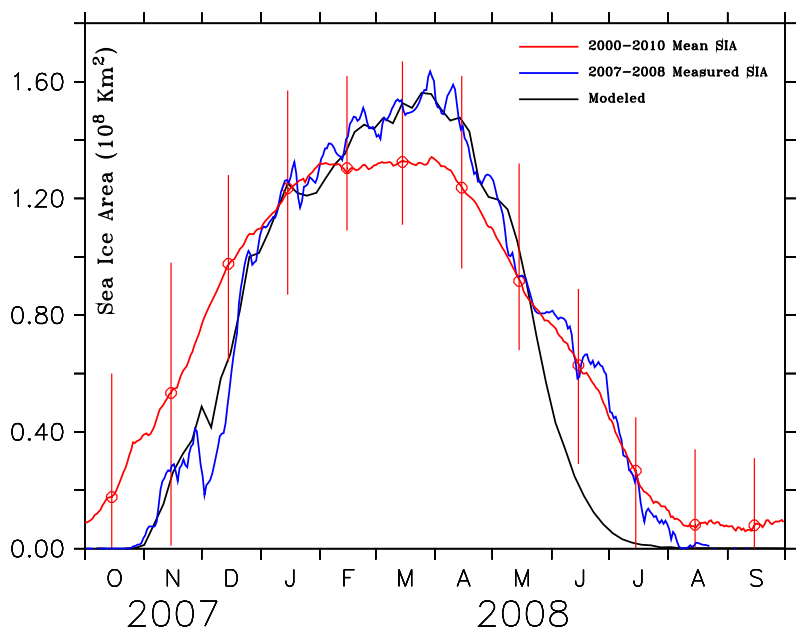

Figure 6. Simulated sea-ice area (black line) and satellitemeasured sea-ice area (blue) over the entire Bering and Chukchi Seas for 2007-2008. The red line denotes the 11 year average area, and the red vertical bars denote the maximum and minimum ice areas during 2000-2011. 
Bering Sea, consistent with the projection by the DA pattern [Wang et al., 2009b, 2013].

[25] Figure 6 shows the comparison between the modeled and measured sea-ice areas during the 2007/2008 winter in
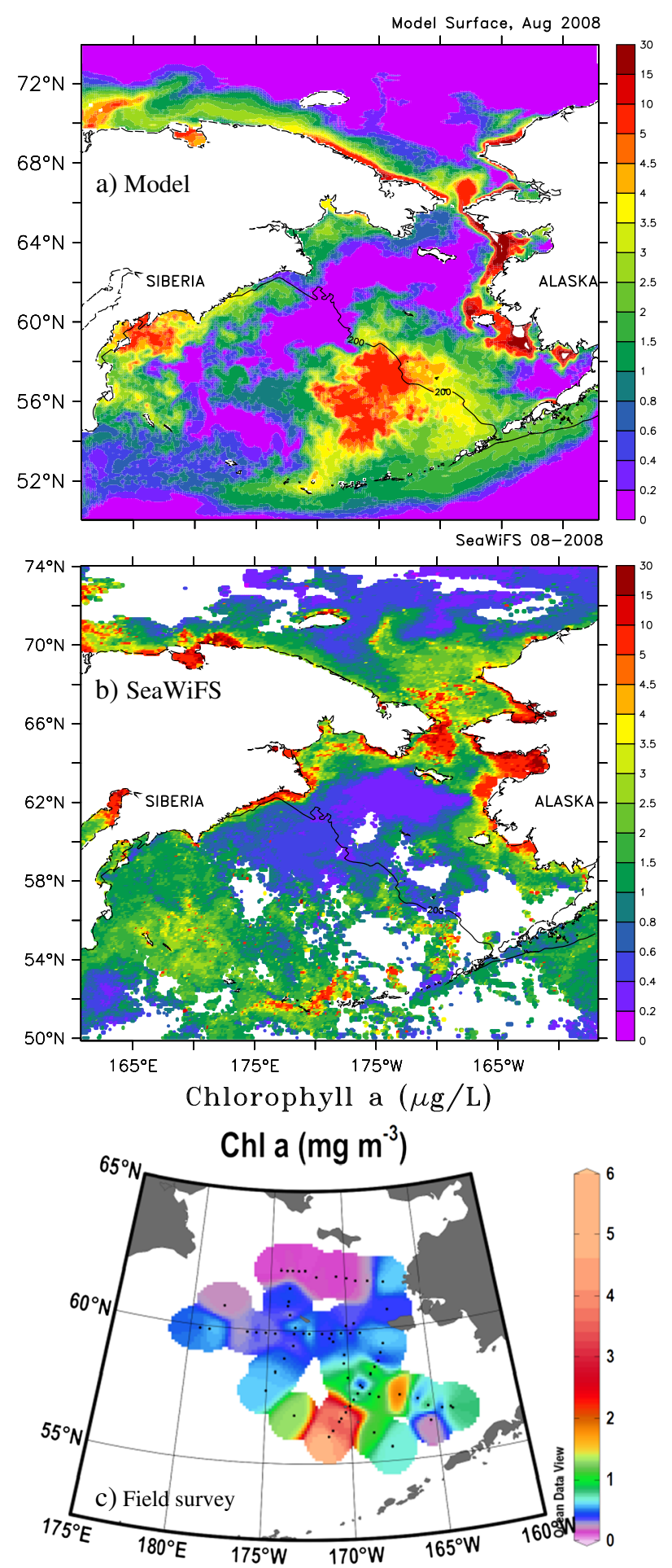

Figure 7. The simulated (a) and SeaWiFs estimated (b) surface chl- $a$ (c) in situ measurement in August 2008. Note that the near continuous measurements of chlorophyll at the surface (c) show the high chlorophyll patch that is reproduced by the model (a) near the shelf break, although the satellite-measurement (b) is not visible due to cloud cover. the Bering and Chukchi Seas. Due to the record low ice extent inside the Arctic Ocean in the summer of 2007, in particular the Pacific sector [Wang et al., 2009b], sea ice had a late freeze-up in autumn 2007, compared to the 11 year climatology (red line). The modeled sea-ice area compares well with the satellite-measured area from November 2007 to March 2008; however, the model produced early melting in springsummer 2008. Note that although the late freeze-up occurred in autumn 2007, it had also occurred before as evidenced by the maximum and minimum sea-ice area denoted by the red vertical bars over the past 11 years.

\subsection{Spatial and Temporal Pattern of Phytoplankton}

[26] The spatial distributions of modeled and satellitemeasured chlorophyll concentration imagery in August 2008 are shown in Figure 7. The model captured high phytoplankton along the Alaskan coast from the Bering to the Chukchi Seas and along the Siberian coast of the Bering Sea (Figure 7a). These modeled features compare favorably to the SeaWiFS chlorophyll concentration data (Figure 7b). Along the AS and ANSC in the vicinity of the Aleutian Islands, both model and measurements show high chlorophyll concentration, suggesting strong biomass activity related to active transport and mixing between Aleutian passages [Maslowski et al., 2008]. In the southwestern Bering deep basin and along the $\mathrm{KC}$, both model and measurements captured high chlorophyll concentration.

[27] A distinct phenomenon is high chl- $a$ concentration along the coasts. After the sea-ice melts and more and more solar radiation is absorbed by the water, water temperature increases faster along the shallow coasts, shelf, and bays than in the deep seas. This favors phytoplankton growth along the coasts and shallow water areas. High chl- $a$ in the Gulf of Anadyr is due to the upwelling along the Siberian coast near Cape Navarin that brings the nutrient-rich water to the surface from the subsurface [Wang et al., 2009a]. The AC also advected nutrient-rich water into the Gulf of Anadyr [Springer et al., 1996]. The modeled bloom was consistent with the satellite-estimated chlorophyll concentration along the ESC.

[28] There were some discrepancies between the model and the satellite chlorophyll concentration estimates. In the eastern basin, the model simulated high chl- $a$, while the measurements were not available due to cloud cover. Note that the satellite chlorophyll concentration was a composite

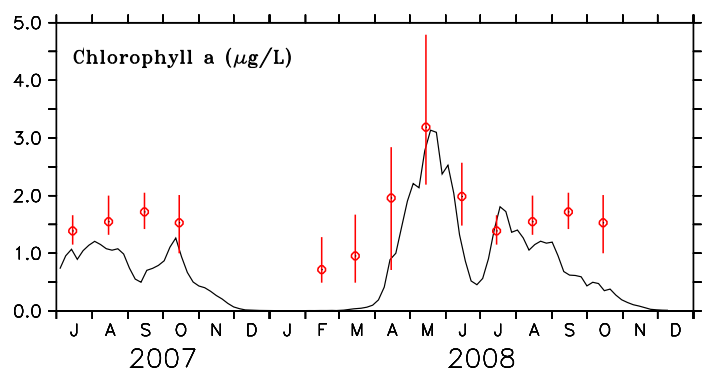

Figure 8. Model-domain averaged chl- $a$, as simulated by the PhEcoM (solid/black line) and measured by SeaWiFs (red circles). The vertical bars denote the monthly maxima and minima derived from the 2000-2010 data. 
average of cloud-free pixels, while the modeled results were strictly a continuous monthly average. The SeaWiFS chl- $a$ algorithm also has an error (officially, $\pm 30 \%$ for global standard algorithm), and its error may become large in the shallow region due to suspended sediment and CDOM), resulting in an over-/underestimation of chl- $a$. An evaluation of the standard NASA SeaWiFS chl- $a$ algorithm (OC4.v6) with field measurements obtained in 2008 does indeed show that for chl- $a$ values $<1 \mathrm{mg} \mathrm{m}^{-3}$, SeaWiFS overestimates chl- $a$ by a factor of $\sim 2$ (and higher at lower chl- $a$ values) due to the dominance of CDOM over phytoplankton absorption (Naik et al., submitted manuscript, 2013).

[29] Monthly averaged satellite chlorophyll concentrations over the entire domain (Figure 8) were calculated using both model simulations and satellite measurements. The model captured the seasonal cycle of the measured chl- $a$ concentration reasonably well. The model reproduced a high peak in May 2008. The simulated concentrations were lower than the measured values. There are large discrepancies from February to April and September to October 2008. This large discrepancy indicates there may be a compartment missing in this simple ecosystem model. A possible reason for the lower concentration in February to April may be due to neglecting the ice algae compartment [Jin et al., 2009] and the input of nutrients from open boundaries. The use of climatological mean nutrient values was not specific to the 2007-2008 bloom event. In addition, satellite estimates of chlorophyll concentration are subject to uncertainty associated with cloud cover, atmospheric correction, water turbidity, and algorithm performance.

\subsection{Vertical Structure}

[30] Shipboard measurements of temperature, salinity, and nutrient concentration are compared to model results along the designated transects in both the Bering and Chukchi Seas. In the Chukchi Sea, the model in general simulates relatively smooth temperature and salinity structure compared to the measurements (Figure 9). The modeled mixed-layer depth was deeper than the observed, possibly due to the fact that there was no sufficient freshwater on the surface that led to weaker stratification. The measured $\mathrm{NO}_{3}$ maximum $(\sim 20 \mu \mathrm{mol} / \mathrm{L})$ is situated right on the bottom of the Chukchi shelf (Figure 9). At $\mathrm{A}_{6}-\mathrm{A}_{7}$, high $\mathrm{NO}_{3}$ water was observed, and the model captured this basic feature but underestimated $\mathrm{NO}_{3}$ concentrations. The model simulated only a thin bottom $\mathrm{NO}_{3}$ layer, compared to the observations. Measurements showed that high $\mathrm{SiO}_{3}$ water is located on the bottom, which the model captured well. A high concentration of nutrients was captured for both the measured and simulated nutrients in the southernmost Chukchi Sea, near the Bering Strait $\left(A_{1}\right)$. This indicates that the nutrient source was from the northern Bering Sea, advected by the Bering Strait outflow.

[31] Temperature, salinity, chlorophyll, and nutrients were measured during 4-23 July 2008, along transect $F$ in the Bering Sea. In summer, stratification develops due to solar
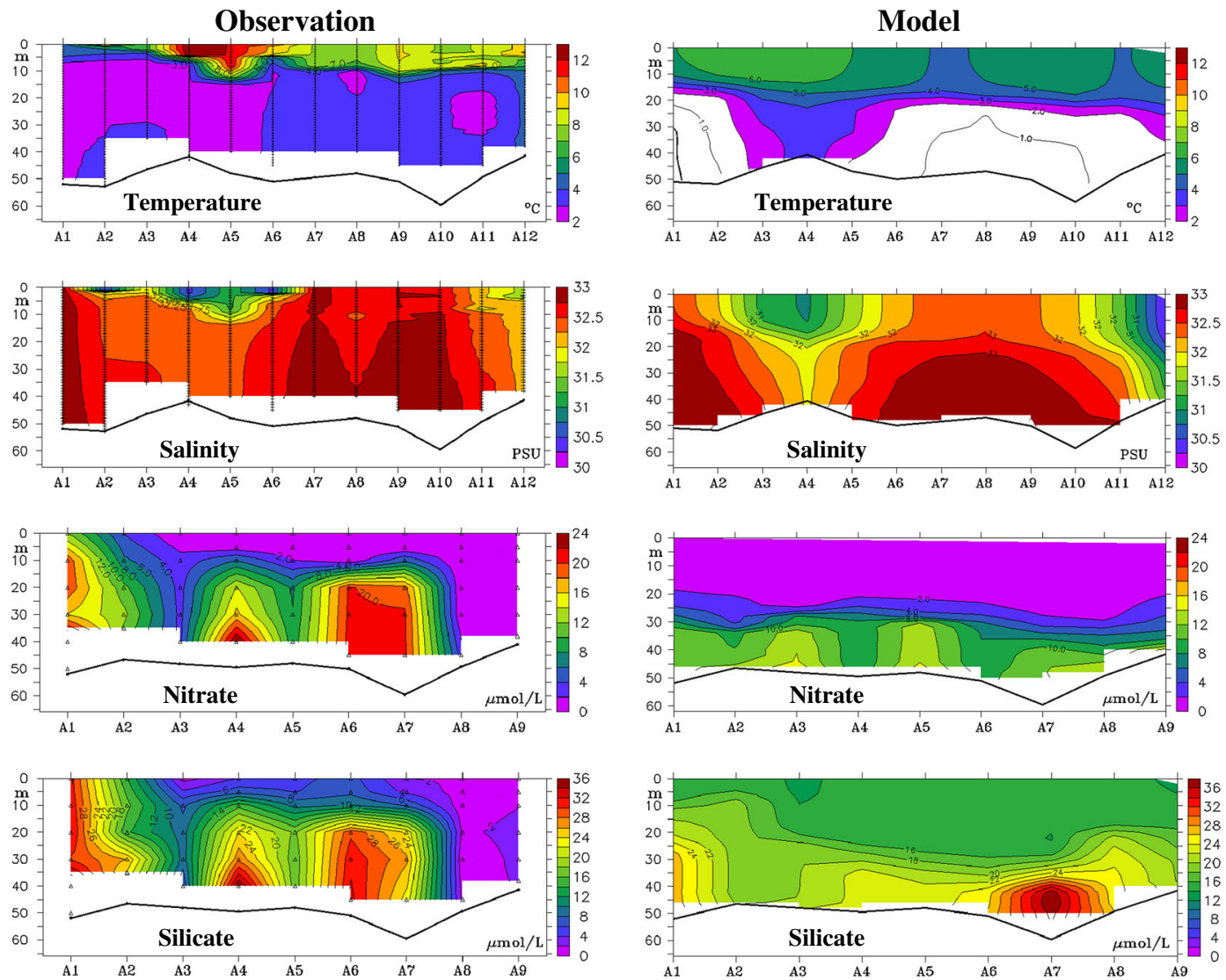

Figure 9. Shipboard-measured (left column) and modeled (right) temperature, salinity, and nutrients (N and Si) along Transect A in the Chukchi Sea (see Figure 1 for location) during the 5-12 August 2007 cruise by T/V Oshoro-Maru. 

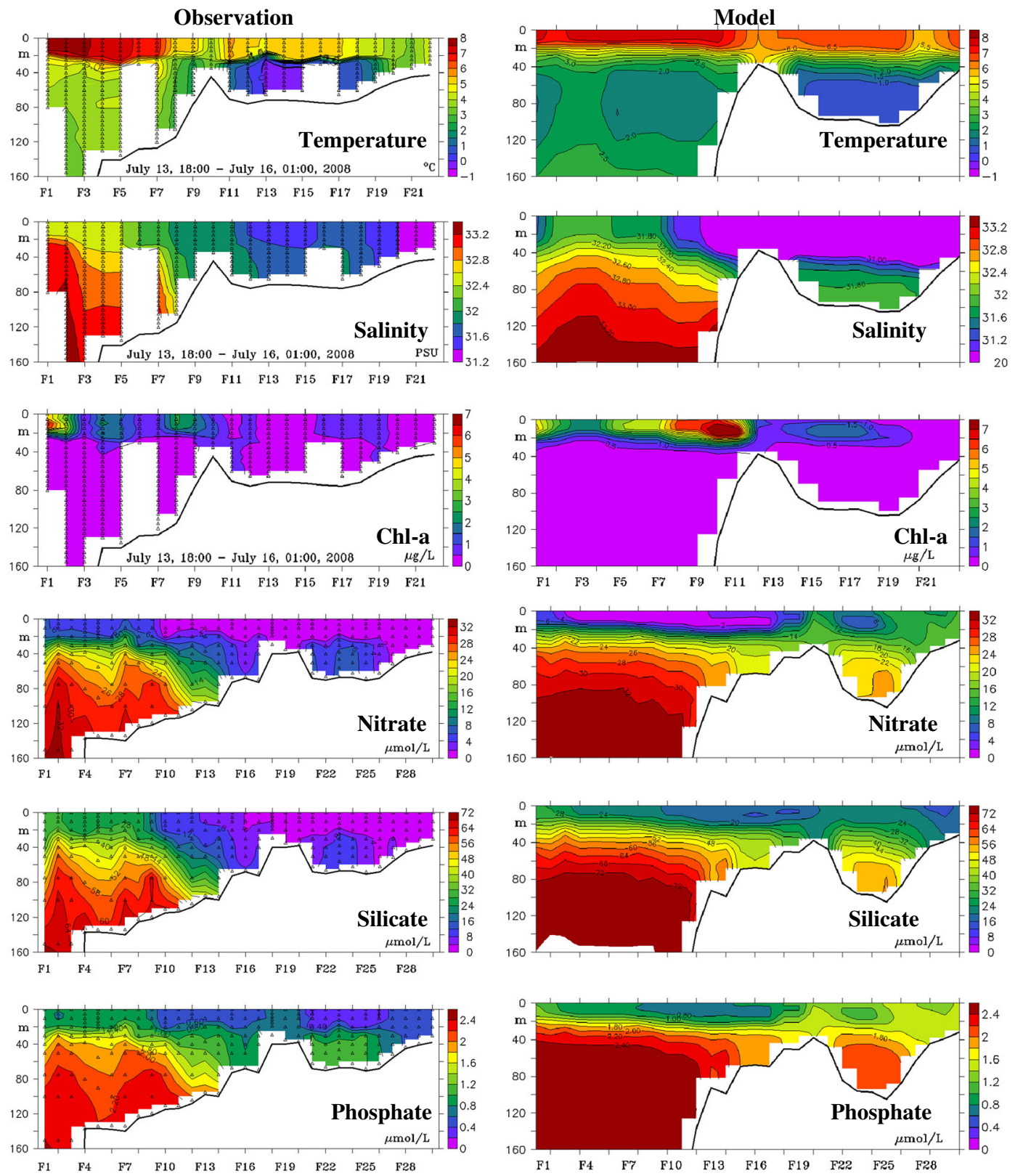

Figure 10. Shipboard-measured (left column) and modeled (right) temperature, salinity, and nutrients (N, Si, P) and chl- $a$ along Transect F in the Bering Sea (see Figure 1 for location) during the 4-23 July 2008 Healy cruise.

radiation, wind mixing in the surface layer, and tidal mixing in the bottom layer on the Bering Shelf [Hu and Wang, 2010] and in the Chukchi Sea. There was a thermal layer of $\sim 20 \mathrm{~m}$ between depths (Figure 10). The model captured well the mixed-layer depth of $\sim 20 \mathrm{~m}$; nevertheless, the model simulated more freshwater near shore. Nutrients in the upper layer were exhausted by phytoplankton, since the thermocline layer inhibits mixing, so that the nutrients can be pumped up from the subsurface to the upper layer by some dynamic processes such as upwelling, mesoscale eddies, and tidal mixing [Mizobata et al., 2006, 2008]. Figure 10 shows the measured and modeled $\mathrm{NO}_{3}$, $\mathrm{SiO}_{3}$, and $\mathrm{PO}_{4}$ along section $\mathrm{F}$ on the Bering shelf (see location in Figure 1). The modeled $\mathrm{NO}_{3}$ distribution reproduced the observations on both the shelf and the shelf break. In July 2008, low $\mathrm{NO}_{3}$ water was measured on the surface of the shelf, and high $\mathrm{NO}_{3}$ water occupied the bottom and shelf break, while the model simulated relatively high $\mathrm{NO}_{3}$ concentration on the surface of the shelf. On the shelf break, the measurements showed that nutrient-rich water was pumped up along the shelf break. The model also reproduced this nutrient pumping $\left(\mathrm{NO}_{3}, \mathrm{SiO}_{3}\right.$, and $\left.\mathrm{PO}_{4}\right)$ in a smoother manner. This indicates that the subsurface nutrients were lifted up to the surface along the shelf break, sustaining blooms on the shelf break or on the Bering Slope. These nutrients should then be advected by the upwelling driven by the southwesterly winds that prevail in summer over the Bering Sea [Wang et al., 2009a, 2013]. Although 


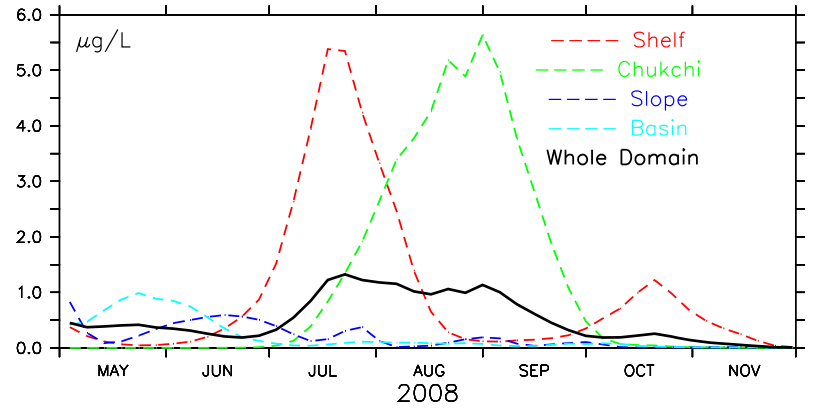

Figure 11. Simulated seasonal variation of phytoplankton (chl- $a$ ) for the subregions and the whole domain.

the overall distribution of nutrients was also reasonably simulated, the model overestimated the magnitudes of $\mathrm{SiO}_{3}$ $\mathrm{NO}_{3}$ and $\mathrm{PO}_{4}$ on the surface of the shelf.

[32] The model captured a thin surface layer of chlorophyll, similar to the measurement along transect $\mathrm{F}$ (Figure 10). The model simulated a higher chl- $a$ concentration on the shelf break than the observed (near $\mathrm{F}_{9}-\mathrm{F}_{11}$ ).

\subsection{Seasonal Variations of Nutrients and Plankton}

[33] To investigate the seasonal variation of phytoplankton, the model domain was divided into the following subregions: deep basin ( $>2000 \mathrm{~m})$, Bering Slope (200 m-2000 m), Bering shelf $(<200 \mathrm{~m})$, and Chukchi shelf. Figure 11 shows the simulated chl- $a$ variations of these subregions and for the whole domain in the upper $100 \mathrm{~m}$ for 2008 . The chlorophyll concentrations showed both amplitudes and seasonal phase lags among these subregions. The deep basins started to bloom first in May, followed by the Bering Slope. The Bering shelf region had a strong bloom in mid July, and the Chukchi Sea bloom occurred in late August and early September. The deep basin and the Bering Slope had comparable magnitude in 2008, showing no significant appearance of the Green Belt bloom, possibly because 2008 (2007-2009) was a cold period with extensive ice extent [Sigler et al., 2011; Wang et al., 2013]. However, the shelf region had a large bloom, peaking in July, possibly due to the higher temperature and easily replenished nutrients in the shallow water, which has less thermal memory than the deep basin [Wang et al., 2013]. This indicates that the physical and biological responses to atmospheric forcing in the Bering shelf and the deep basins are different in terms of thermal memory. The Chukchi Sea experienced the second largest bloom when compared to the Bering Slope and deep

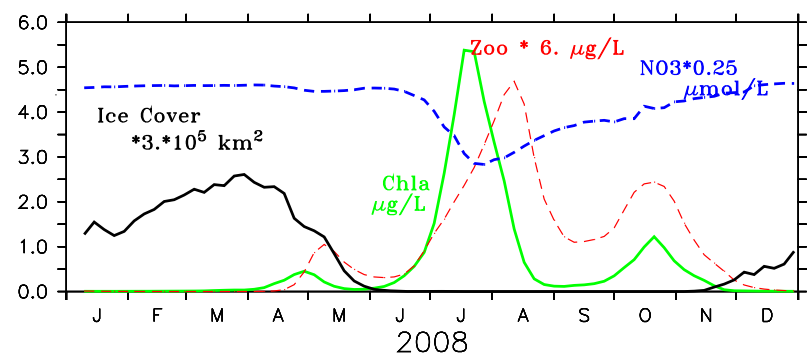

Figure 12. Modeled seasonal variations of sea-ice cover (black line), nitrate (blue dashed), chl- $a$ (green), and zooplankton (red dashed) over the entire Bering and Chukchi Seas. The units and factors are given. basins, with a significant phase lag to the Bering shelf, because sea ice retreated from south to north, which controlled the water temperature changes.

[34] To reveal the relationship between ice cover (i.e., temperature) and phytoplankton blooms in the Bering shelf, the seasonal variations of sea-ice area, domain-averaged nutrients, phytoplankton, and zooplankton are shown in Figure 12. Sea ice reached a maximum in late March and started to retreat in April 2008. With ice retreating, water temperature increased and light availability for photosynthesis increased, resulting in phytoplankton growth and nutrient absorption, which was followed by a zooplankton bloom that grazed down phytoplankton. The simulated seasonal cycle of the plankton food web dynamics over the shelf was consistent with the measurements.

\section{Sensitivity Studies and Discussion}

[35] Sensitivity studies were conducted to reveal the underlying mechanisms of the biological-physical interactions: (1) an increase in light intensity by increasing shortwave solar radiation by $10 \%$ to show the response of plankton to the climate change, a bottom-up effect, (2) a $20 \%$ increase in nutrients around the open boundaries applied to examine the response of the biological system inside the Bering-Chukchi Seas to outside nutrient loadings, which are considered a major uncertainty, and (3) an increase in air temperature over the entire simulation period from 2007 to 2008 .

\subsection{Increase in Light Intensity}

[36] To test the sensitivity of the coupled physical and biological system to the change in light intensity, a $10 \%$ increase in solar radiation was applied uniformly to the solar radiation over the entire simulation period. Table 2 shows the difference between this run and the control run in chl- $a$ concentration over the four geographic subregions and the entire domain. Compared to the control run (Figure 11), the overall response to a $10 \%$ increase in light intensity is not significant (Table 2, third column), since the light is not a limiting factor in the Bering and Chukchi Seas. The duration and light intensity from late spring to late summer are sufficient for plankton growth. The chl- $a$ in the whole Bering and Chukchi Seas only increases less than $1 \%$ with

Table 2. Subdomain- and Time- (May-November) Average chl- $a$ Comparison Between the Sensitivity Experiments and the Control Run (Second Column) for (1) an Increase of Solar Radiation by 10\% (Third Column), (2) an Increase of Nutrients From Open Boundaries (OB) by $20 \%$ (Fourth Column), and (3) an Increase of Air Temperature by $2{ }^{\circ} \mathrm{C}$ (Fifth Column) ${ }^{\mathrm{a}}$

\begin{tabular}{lcccc}
\hline $\begin{array}{l}\text { chl- } a \\
(\mu \mathrm{g} / \mathrm{L})\end{array}$ & $\begin{array}{c}\text { Standard } \\
\text { Run }\end{array}$ & $\begin{array}{c}\text { Solar Radiation } \\
\text { Increased } \\
\text { by } 10 \%\end{array}$ & $\begin{array}{c}\text { OB Nutrients } \\
\text { Increased } \\
\text { by } 20 \%\end{array}$ & $\begin{array}{c}\text { Air Temperature } \\
\text { Increased } \\
\text { by } 2{ }^{\circ} \mathrm{C}\end{array}$ \\
\hline Basin & 0.204 & $0.003(1.47 \%)$ & $0.050(24.5 \%)$ & $-0.035(-17.15 \%)$ \\
Slope & 0.186 & $0.008(4.30 \%)$ & $0.096(51.6 \%)$ & $0.041(22.04 \%)$ \\
Shelf & 0.987 & $0.005(0.51 \%)$ & $0.051(5.10 \%)$ & $0.135(13.66 \%)$ \\
Chukchi & 1.160 & $0.002(0.17 \%)$ & $0.016(1.30 \%)$ & $0.220(18.97 \%)$ \\
Whole & 0.507 & $0.004(0.78 \%)$ & $0.035(6.90 \%)$ & $0.054(10.65 \%)$ \\
\hline
\end{tabular}

${ }^{\mathrm{a}}$ Numbers in parentheses are the relative increase rate, and numbers in columns $3-5$ are the differences between the sensitivity runs and the control run. 
Table 3. Bering Shelf Domain- and Time- (May-November) Average Comparison Between the Sensitivity Experiments and the Control Run (Second Column) for (1) an Increase of Solar Radiation by 10\% (Third Column), (2) an Increase of Nutrients From Open Boundaries (OB) by $20 \%$ (Fourth Column), and (3) an Increase of Air Temperature by $2{ }^{\circ} \mathrm{C}$ (Fifth Column) ${ }^{\mathrm{a}}$

\begin{tabular}{|c|c|c|c|c|}
\hline Variables & Standard Run & Solar Radiation Increased by $10 \%$ & OB Nutrients Increased by $20 \%$ & Air Temperature Increased by $2^{\circ} \mathrm{C}$ \\
\hline Ice Cover $\left(\mathrm{km}^{2}\right)$ & $2.20 \times 10^{5}$ & $-2.97 \times 10^{3}(-1.35 \%)$ & & $-2.32 \times 10^{4}(-10.56 \%)$ \\
\hline $\operatorname{chl}-a(\mu \mathrm{g} / \mathrm{L})$ & 0.987 & $0.005(0.51 \%)$ & $0.051(5.10 \%)$ & $0.135(13.66 \%)$ \\
\hline Zoopl. $(\mu \mathrm{g} / \mathrm{L})$ & 0.272 & $-0.012(-4.42 \%)$ & $0.016(5.89 \%)$ & $0.055(20.08 \%)$ \\
\hline $\mathrm{NO} 3(\mu \mathrm{mol} / \mathrm{L})$ & 15.71 & $0.194(1.23 \%)$ & $1.612(10.3 \%)$ & $5.053(32.16 \%)$ \\
\hline
\end{tabular}

${ }^{\mathrm{a}}$ Numbers in parentheses are the relative increase rate, and numbers in columns 3-5 are the differences between the sensitivity runs and the control run.

the slope region being the largest $(4.3 \%)$, and the basin the second largest $(1.5 \%)$. Due to an increase of solar radiation over a seasonal cycle (Table 3, column 3), Bering shelf sea ice reduced by only $-1.4 \%$; chl- $a$ increases remained almost the same as the control run; zooplankton decreased by $4.4 \%$; and nutrients increased by only $1.2 \%$.

[37] In summary, a $10 \%$ increase in solar radiation has a small impact on phytoplankton growth, since light is not a limiting factor for plankton growth in the spring-summer season in the Bering and Chukchi Seas.

\subsection{Increase in Nutrients From Open Boundaries}

[38] With a $20 \%$ increase in all the nutrients from open boundaries (Table 2, column 4), it is found that the most significantly impacted area is the Slope (51.6\%), since the Slope region is the area where nutrients from open boundaries upstream (i.e., from the AS) are advected faster than other regions via a number of passes along the Aleutian Islands [Hu and Wang, 2010]. The second largest area impacted was the basin, which had a $25 \%$ increase. The deep basins are closely connected with the passes along the Aleutian Islands and the Slope Current systems: the ANSC and the BSC. The high nutrients along the slope currents can be advected to the deep basins via the shelf-basin exchange [Clement Kinney et al., 2009] and mesoscale eddy transport [Mizobata and Saitoh, 2004; Mizobata et al., 2006, 2008]. By contrast, the Bering shelf has a 5\% increase, and the Chukchi Sea has a $1.3 \%$ increase. This indicates that the slope ecosystem and the shelf ecosystem are quite different or somewhat isolated in response to the upstream nutrient increase (or supply).

[39] Over the Bering shelf (Table 3, column 4), the average nutrients increase by $10 \%$, the chl- $a$ increases by $5 \%$, and zooplankton increases by $6 \%$. Therefore, the response to the $20 \%$ increase in nutrients at the open boundaries is significant. In other words, the nutrient input from the open boundaries should be adequately prescribed in order to accurately simulate the plankton bloom and biomass inside the Bering Sea. Therefore, a $20 \%$ error in nutrient input along the open boundaries can lead to a large discrepancy in the Bering Sea.

\subsection{Increase in Air Temperature}

[40] Surface air temperature is a major driver to the marine physical environment and to the ecosystem [Overland and Stabeno, 2004; Grebmeier et al., 2010], which is controlled by regional and teleconnection climate patterns, such as the Arctic Oscillation [Wang and Ikeda, 2000, 2001], the Pacific-North America pattern during an ENSO event
[Wallace and Gutzler, 1981], and the Decadal Pacific Oscillation [Mantua et al., 1997].

[41] An increase in air temperature by $2{ }^{\circ} \mathrm{C}$ over the domain shows an overall $11 \%$ increase in phytoplankton (chl- $a$ ) in the whole domain (see Table 2, last column). Large, comparable responses occurred in all the regions: in the Slope $(22 \%)$, Chukchi Sea $(19 \%)$, Basin $(-17 \%)$, and Bering shelf (14\%) regions. The overall change was $11 \%$ in chl- $a$. This bottom-up effect is significant, since the grazing rates are temperature dependent with the available nutrients. The decrease in chl- $a$ in the deep basin was difficult to explain, which may be associated with the changes in ocean circulation, horizontal and vertical heat transport, and vertical mixing.

[42] With a $2^{\circ} \mathrm{C}$ increase in air temperature (Table 3, last column), sea ice reduced by $11 \%$, nutrients increased by $32 \%$, phytoplankton (chl- $a$ ) increased by $13 \%$, and zooplankton increased by $20 \%$. Again, the increase of air temperature (i.e., water temperature) has a bottom-up effect on the entire ecosystem in the Bering and Chukchi Seas, compared to an increase in light intensity.

\section{Concluding Remarks}

[43] The 3-D NPZD model was coupled to the CIOM to simulate the ecosystem in the Bering and Chukchi Seas. The model was run for 2007 and 2008, and the results were compared with field measurements from two IPY cruises. Based on the above discussion, major results can be summarized as follows:

[44] 1. Seasonal cycle of sea ice, ocean circulation, and temperature in the Bering and Chukchi Seas are reasonably reproduced. Although 2007 and 2008 were record low ice years in the Arctic summer, the Bering Sea ice experienced a normal ice year, with the ice edge being close to the climatology. The simulated volume transport via the Bering Strait compared reasonably well to the observations. The seasonal cycle of the Bering and Chukchi Seas lower trophic level ecosystem was reasonably simulated using the simple NPZD ecosystem model.

[45] 2. Sea-ice retreat (i.e., the increase of water temperature) controls the timing of the plankton blooms from the south to the north: deep basin, Bering Slope to the Bering shelf, and then to the Chukchi Sea. The bloom on the Bering shelf was stronger than on the Bering Slope and in the deep basin in the summer of 2008. No anomalous bloom along the Green Belt (Bering Slope) was found in either the in situ and satellite measurements or in the modeling results. The Chukchi Sea bloom occurred in late August to early 
September, accompanying the sea-ice retreat or the increase of temperature.

[46] 3. Along the Chukchi shelf section A during 5-12 August 2007, nutrient-rich water was located on the bottom, and maximum chl- $a$ was located at the subsurface, as captured by the model in general. However, the model underestimated the magnitude of the blooms.

[47] 4. Across the Bering Slope (i.e., along transect F) during 4-23 July 2008, nutrient-rich water was observed in the subsurface, which reflects nutrient upwelling to the surface. Across the Bering Slope, a thin layer of chlorophyll was situated on the surface, as also simulated by the model.

[48] Sensitivity studies show that a $10 \%$ increase in solar radiation or light intensity for the entire year has a small impact on the intensity and timing of the bloom in the physicalbiological system since the light is not a limiting factor in the study region. A $20 \%$ increase in nutrients from all the open boundaries results in an overall $7 \%$ increase in phytoplankton, with the Slope region being the largest, and the Bering shelf and Chukchi being the smallest. This indicates that (1) the Slope and Bering shelf ecosystems respond differently to the nutrient input from the open boundaries and (2) the ecosystem inside the Bering Sea is significantly influenced by the nutrient input from the open boundaries. In other words, a $20 \%$ error in nutrients prescribed on the open boundaries can result in a $7 \%$ error or uncertainty in the study region, and even more so along the slope (52\%) and basin $(25 \%)$ regions. Therefore, monthly, or at least seasonal nutrient input from open boundaries is required for a NPZD model to accurately reproduce the ecosystem inside the study region. An increase in air temperature by $2{ }^{\circ} \mathrm{C}$ over the entire calculation period, a bottom-up effect, can result in an overall increase in phytoplankton by $11 \%$. In other words, a persistent warming [Overland and Stabeno, 2004] in the regional climate for several years in a row can have significant impacts on the ecosystem in the Bering and Chukchi Seas. Nevertheless, this sensitivity of the ecosystem to air temperature requires accurate atmospheric forcings including air temperature, cloud cover, and heat fluxes, since an error of $2^{\circ} \mathrm{C}$ in air temperature can lead to an $11 \%$ change (error) in the Bering and Chukchi ecosystems.

[49] Large discrepancies exist between the modeled results and the measurements, in particular along Transect A in the Chukchi Sea. As discussed above, there are many sources of uncertainty involving the coupled models. The major weakness is the salinity or freshwater simulation due to lack of accurate evaporation and precipitation forcing from the NCEP reanalysis, similar to most models. Utilizing available climatological nutrient data to initialize and constrain the NPZD model from the outer boundaries, the model captured the basic structure of the measurements in 2008; the existing differences between the model and the data should be not surprising. An urgent effort is needed to compile a monthly or at least seasonal gridded dataset using historical in situ and satellite measurements. With the initialization and constraint of the boundaries using at least the seasonal gridded dataset, the regional ecosystem models will be significantly improved in a realistic setting.

[50] Acknowledgments. We appreciate support from NOAA RUSALCA (Russian-American Long-term Census of the Arctic) International Polar Year modeling project and NASA Interdisciplinary Science award NNX10AP10G. We appreciate two anonymous reviewers for their constructive comments that helped improve the article. Thanks also go to Cathy Darnell for editing a draft. This is GLERL Contribution No. 1651.

\section{References}

Blumberg, A. F., and G. L. Mellor (1987), A description of 3-D coastal ocean circulation model. In Coastal and Estuarine Sciences 4: 3-D Coastal Ocean Models, edited by Heaps, N.S., pp 1-16American Geophysical Union, Washington DC.

Brown, Z. W., G. L. van Dijken, and K. R. Arrigo (2011), A reassessment of primary production and environmental change in the Bering Sea, $J$. Geophys. Res., 116, C08014, doi:10.1029/2010JC006766.

Clement Kinney, J., W. Maslowski, and S. Okkonen (2009), On the processes controlling shelf basin exchange and outer shelf dynamics in the Bering Sea, Deep-Sea Res.,II, 56, 1351-1362.

Clement Kinney J., et al. (2013), On the flow through Bering Strait: A synthesis of model results and observations. In The Pacific Arctic Region: Status and trends in a rapidly changing environment, edited by J. M. Grebmeier, and W. Maslowski, Springer, accepted.

Coachman, L. K., and D. A. Handell (1993), ISHTAR, Inner Shelf Transfer and Recycling in the Bering and Chukchi Seas (ed.), Continen. Shelf. Res., 13, 473-703.

Danielson, S., E. Curchitser, K. Hedstrom, T. Weingartner, and P. Stabeno (2011), On ocean and sea ice modes of variability in the Bering Sea, $J$. Geophys. Res., 116, C12034, doi:10.1029/2011JC007389.

Deal, C. J., et al., (2013), Progress and Challenges in Biogeochemical Modeling of the Pacific Arctic Region, in The Pacific Arctic Region: Ecosystem Status and Trends in a Rapidly Changing Environment, edited by J. M. Grebmeier and W. Maslowski, Springer Publishing, accepted.

Eppley, R. W. (1972), Temperature and phytoplankton growth in the sea, Fish. Bull., 70, 1063-1085.

Eslinger, D. L., and R. L. Iverson (2001), The effects of convective and wind mixing on springtime phytoplankton dynamics in the southeastern Bering Sea shelf, Continental Shelf Res., 21, 627-650.

Eslinger, D. L., R. T. Cooney, C. P. McRoy, A. Ward, T. Kline, E. P. Simpson, J. Wang, and J. R. Allen (2001), Plankton dynamics: Observed and modeled response to physical forcing in Prince William Sound, Alaska, Fisheries Oceanogr., 10 (Suppl. 1), 81-96.

Ezer, T., and L.-Y. Oey (2010), The role of the Alaskan Stream in modulating the Bering Sea climate, J. Geophys. Res., 115, C04025, doi:10.1029/ 2009JC005830

Grebmeier, J. M., S. E. Moore, J. E. Overland, K. E. Frey, and R. Gradinger (2010), Biological response to recent Pacific Arctic sea ice retreats, Eos, Amer. Geophys. Union Trans., 91(18), 161-162.

Griffiths, C., M Ikeda, and P. C. Smith (2000), A numerical model comparison of baroclinic instability in the presence of topography, Tellus $52 \mathrm{~A}$, 42-65.

Hibler, W. D. III (1979), A dynamic and thermodynamic sea ice model, J. Phys. Oceanogr., 9, 15,959-15,969.

Hibler, W. D. III (1980), Modeling a variable thickness sea ice cover, Mon Wea Rev., 108, 1943-1973.

Hu, H., Z. Wan, and Y. Yuan (2004), Simulation of seasonal variation of phytoplankton in the South Yellow Sea and analysis on its influential factors. Acta Oceanologica Sinica (In Chinese with an English abstract), $6,74-88$

$\mathrm{Hu}, \mathrm{H}$, and J. Wang (2010), Modeling effects of tidal and wave mixing on circulation and thermohaline structures in the Bering Sea: Process studies, J. Geophys. Res., 115, C01006, doi:10.1029/2008JC005175.

Hu, H., J. Wang, and D.R. Wang (2011), A model-data study of the $1999 \mathrm{St}$ Lawrence polynya in the Bering Sea, J. Geophys. Res., 116, C12018, doi:10.1029/2011JC007309.

Ikeda, M. (1983), Linear instability of a current flowing along a bottom slope using a three-layer model, J. Phys. Oceanogr., 13: 208-223.

Ivlev, V. S. (1945), The biological productivity of waters, Usp. Sovrem. Biol., 19, 98-120.

Jin, M., C .J. Deal, J. Wang, N. Tanaka, and M. Ikeda (2006a), Vertical mixing effects on the phytoplankton bloom in the southeastern Bering Sea midshelf, J. Geophys. Res., 111, C03002, doi:10.1029/2005JC002994

Jin, M., C. J. Deal, J. Wang, K.-H. Shin, N. Tanaka, T. Whitledge, S. H. Lee, and R. R. Gradinger (2006b), Controls of the landfast ice-ocean ecosystem offshore Barrow, Alaska, Annals of Glaciology, 44, 63-72.

Jin, M., C. Deal, J. Wang, V. Alexander, R. Gradinger, S. Saitoh, T. Iida, Z. Wan, and P. Stabeno (2007), Ice-associated phytoplankton blooms in the southeastern Bering Sea, Geophys. Res. Lett., 34 , L06612, doi:10.1029/2006GL028849.

Jin, M., C. Deal, J. Wang, and P. McRoy (2009), Responses of lower trophic level productivity to long-term climate changes in the southeastern Bering Sea, 1960-2007, J. Geophys. Res., 114, C04010, doi:10.1029/ 2008JC005105. 
Jin, M., C. Deal, S. H. Lee, S. Elliott, E. Hunke, M. Maltrud, and N. Jeffery (2011), Investigation of Arctic sea ice and ocean primary production for the period 1992-2007 using a 3-D global ice-ocean ecosystem model, Deep-Sea Res. II, doi:10.1016/j.dsr2.2011.06.003.

Long, Z., W. Perrie, C. L. Tang, E. Dunlap, and J. Wang (2012), Simulated interannual variations of freshwater content and sea surface height in the Beaufort Sea, J. Clim., doi: 10.1175/2011JCI14121.1.

Mantua, N. J., S. R. Hare, Y. Zhang, J. M. Wallace, and R. C. Francis (1997), A Pacific interdecadal climate oscillation with impacts on salmon production, Bulletin of the American Meteological Society, 78, 1069-1078.

Maslowski, W., R. Roman, and J. C. Kinney (2008), Effects of mesoscale eddies on the flow of the Alaskan Stream, J. Geophys. Res., 113, C07036, doi:10.1029/2007JC004341.

Mellor, G. L. (2004), Users guide for a 3-D, primitive equation, numerical ocean model. Atmospheric and Oceanic Sciences Program, Princeton Univ. (Princeton, NJ 08540), 56.

Mellor, G. L., and L. Kantha (1989), An ice-ocean coupled model, J. Geophys. Res., 94, 10,937-10,954.

Mizobata, K., and S. Saitoh (2004), Variability of Bering Sea eddies and primary productivity along the shelf edge during 1998-2000 using satellite multi-sensor remote sensing, J. Mar. Sys., 50, 101-111.

Mizobata, K., S. Saitoh, S. Shiomoto, T. Miyamura, N. Shiga, M. Toratani, Y. Kajiwara, and K. Sasaoka (2002), Bering Sea cyclonic and anticyclonic eddies observed during summer 2000 and 2001, Prog. Oceanogr., 55 , $65-75$

Mizobata, K., J. Wang, and S. Saitoh (2006), Eddy-induced cross-slope exchange maintaining summer high productivity of the Bering Sea shelf break, J. Geophys. Res., 111, C10017, doi:10.1029/2005JC003335.

Mizobata, K., S. Saitoh, and J. Wang (2008), Interannual variability of summer biochemical enhancement in relation to the mesoscale eddy at the shelf break in the vicinity of the Pribilof Islands, Bering Sea, Deep Sea Res., doi:10.1016/j.dsr2.2008.03.002.

Mizobata, K., K. Shimada, S. Saitoh, and J. Wang (2010), Estimation of heat flux through the eastern Bering Strait, J. Oceanogr. 66(3) 405-424 doi:10.1007/s10872-010-0035-7.

Mizobata, K., J. Wang, H. Hu, and D. R. Wang (2011), Low primary productivity in the Chukchi Sea controlled by warm Pacific water: A data-model fusion study. In Remote Sensing of the Changing Oceans, chapter 12. Edited by, D. Tang, Springer, 239-250.

Niebauer, H. J. (1980), Sea ice and temperature variability in the eastern Bering Sea and relation to atmospheric fluctuations, J. Geophys. Res. $85,7507-7515$.

Oguz, T., H. Ducklow, and P. Malanotte-Rizzoli, et al. (1996), Simulation of annual plankton productivity cycle in the Black Sea by a one-dimensional physical-biological model, J. Geophys. Res., 101, 16,585-16,599.

Okkonen, S. R., G. M. Schmidt, E. D. Cokelet, and P. J. Stabeno (2004), Satellite and hydrographic observations of the Bering Sea 'Green Belt', Deep-Sea Res. II, 51, 1033-1051.

O'Reilly, J., S. Maritorena, B. Mitchell, D. Siegel, K. Carder, S. Garver, M Kahru, and C. McClain (1998), Ocean color chlorophyll algorithms for SeaWiFS, J. Geophys. Res, 103(C11), 24,937-24,953.

Overland, J. E., and P. J. Stabeno (2004), Is the climate of the Bering Sea warming and affecting the ecosystem?, Eos, Amer. Geophys. Union Trans, 85(33), 309-316.

Overland, J. E., J. Wang, R. S. Pickart, and M. Wang (2013), Recent and future change in the meteorology of the Pacific Arctic In: The Pacific Arctic Region: Ecosystem Status and Trends in a Rapidly Changing Environment, edited by J. M. Grebmeier and W. Maslowski, Springer Publishing, accepted.

Platt., T, C. L. Gallegos, and W. G. Harrison, (1980), Photoinhibition of photosynthesis in natural assemblages of marine phytoplankton, J. Mar Res. 38, 687-701.

PMEL (2000), FY 2000 Operating Plan: http:/www.pmel.noaa.gov/home/ accomp/opplan00.html

Sigler, M. F., M. Renner, S. L. Danielson, L. B. Eisner, R. R. Lauth, K. J. Kuletz, E. A. Logerwell, and G. L. Hunt, Jr. (2011), Fluxes, finds, and feathers: Relationships among the Bering, Chukchi, and Beaufort Seas in a time of climate change, Oceanography, 24, 250-265.

Spall, M. A. (2007), Circulation and water mass transformation in a model of the Chukchi Sea, J. Geophys. Res., 112, C05025, doi:10.1029/ 2005JC003364.

Springer, A. M., C. P. McRoy, and M. V. Flint (1996), The Bering Sea Green Belt: shelf-edge processes and ecosystem productivity, Fisheries Oceanography, 35, 205-223.

Stabeno, P. J., J. D. Schumacher, and K. Ohtani (1999), The physical oceanography of the Bering Sea. In Dynamics of the Bering Sea, North Pacific Marine Science Organization (PICES), edited by, T. R. Loughlin and K. Ohatani, published by University of Alaska Sea Grant Fairbanks, Alaska, pp. 1-28.
Steele, M., R. Rebecca, and W. Ermold (2001), PHC: A global ocean hydrography with a high-quality Arctic Ocean, J. Clim., 14, 2079-2087.

Tang, C. L. (2008), A coupled multi-category sea ice model and POM for Baffin Bay and the Labrador Sea, Chinese Journal of Polar Science, 19(2), 149-158

Throndike, A. S., D. A. Rothrock, G. A. Maykut, and R. Colony (1975), The thickness distribution of sea ice, J. Geophys. Res., 80, 4501-4513.

Wallace, J. M., and D. S. Gutzler (1981), Teleconnections in the geopotential height field during the Nothern Hemisphere winter, Mon. Wea. Rev., 109, 784-812.

Wang J. (1996), Global linear stability of the two-dimensional shallow-water equations: Application of the distributive theorem of roots for polynomials on the unit circle, Mon. Wea. Rev., 124(6): 1301-1310.

Wang, J., L. A. Mysak, and R. G. Ingram (1994), A numerical simulation of sea-ice cover in Hudson Bay, J. Phys. Oceanogr., 24(12), 2515-2533.

Wang, J., and M. Ikeda (1997), Diagnosing ocean unstable baroclinic waves and meanders using quasi-geostrophic equations and Q-vector method, J. Phys. Oceanogr., 27, 1157-1172.

Wang, J., and M. Ikeda (2000), Arctic Oscillation and Arctic Sea-Ice Oscillation, Geophys. Res. Lett., 27(9), 1287-1290.

Wang, J., and M. Ikeda (2001), Arctic Sea-Ice Oscillation: Regional and seasonal perspectives, Annals of Glaciology, 33, 481-492.

Wang, J., Q. Liu, and M. Jin (2002), A User's Guide for a Coupled IceOcean Model $(C I O M)$ in the Pan-Arctic and North Atlantic Oceans. International Arctic Research Center-Frontier Research System for Global Change, Tech. Rep. 02-01,65 pp. (available at Jia.Wang@ noaa.gov)

Wang, J., C. Deal, Z. Wan, M. Jin, N. Tanaka, and M. Ikeda (2003a), User's Guide for a Physical-Ecosystem Model (PhEcoM) in the Subpolar and Polar Oceans. International Arctic Research Center-Frontier Research System for Global Change, Tech. Rep. 02-02, 69 pp. (available at Jia. Wang@noaa.gov)

Wang, J., et al., (2003b), Working towards improved small-scale sea ice and ocean modeling in the Arctic seas. EOS, AGU, Vol. 84(34), 325, 329-330.

Wang, J., B. Wu, C. Tang, J. E. Walsh, and M. Ikeda (2004), Seesaw structure of subsurface temperature anomalies between the Barents Sea and the Labrador Sea, Geophys. Res. Lett., 31, L19301, doi:10.1029/2004GL019981.

Wang, J., M. Ikeda, S. Zhang, and R. Gerdes (2005a), Linking the northern hemisphere sea ice reduction trend and the quasi-decadal Arctic Sea Ice Oscillation, Climate Dyn., 24, 115-130, doi:10.1007/s00382004-0454-5

Wang, J., Q. Liu, M. Jin, M. Ikeda, and F. J. Saucier (2005b), A coupled ice-ocean model in the pan Arctic and the northern North Atlantic Ocean Simulation of seasonal cycles, J. Oceanogr., 61, 213-233.

Wang, J. K. Mizobata, H. Hu, M. Jin, S. Zhang, W. Johnson, and K. Shimada (2008), Modeling seasonal variations of ocean and sea ice circulation in the Beaufort and Chukchi Seas: A model-data fusion study, Chinese Journal of Polar Science, 19(2), 168-184.

Wang, J., H. Hu, K. Mizobata, and S. Saitoh (2009a), Seasonal variations of sea ice and ocean circulation in the Bering Sea: A model-data fusion study, J. Geophys. Res., 114, C02011, doi:10.1029/2008JC004727.

Wang, J., J. Zhang, E. Watanabe, K. Mizobata, M. Ikeda, J. E. Walsh, X. Bai, and B. Wu (2009b), Is the Dipole Anomaly a major driver to record lows in the Arctic sea ice extent?, Geophys. Res. Lett., 36, L05706, doi:10.1029/2008GL036706.

Wang, J., H. Eicken, Y. Yu, X. Bai, J. Zhang, H. Hu, D.-R. Wang, M Ikeda, K. Mizobata, and J. E. Overland (2013), Abrupt climate changes and emerging ice-ocean processes in the Pacific Arctic Region and the Bering Sea. In The Pacific Arctic Region: Status and trends in a rapidly changing environment, edited by J. M. Grebmeier and W. Maslowski, Springer, accepted.

Watanabe, E., J. Wang, T. Sumi, and H. Hasumi (2006), Arctic Dipole and its contribution to sea ice exports in the 20th century, Geophys. Res. Lett. 33, L23703, doi:10.1029/2006GL028112.

Woodgate, R. A., and K. Aagaard (2005), Revising the Bering Strait freshwater flux into the Arctic Ocean, Geophys. Res. Lett., 32, L02602, doi:10.1029/2004GL021747.

Woodgate, R., T. J. Weingartner, and K. Aagaard (2005), A year in the physical oceanography of the Chukchi Sea: Moored measurements from autumn 1990-1991, Deep Sea Res. II, 3116-3149.

Woodgate, R. A., T. Weingartner, and R. Lindsay (2010), The 2007 Bering Strait oceanic heat flux and anomalous Arctic sea-ice retreat, Geophys. Res. Lett., 37, L01602, doi:10.1029/2009GL041621.

Wu, B., J. Wang, and J. E. Walsh (2006), Dipole anomaly in the winter Arctic atmosphere and its association with Arctic sea ice motion, J. Clim., 19(2), 210-225 doi:10.1175/JCLI3619.1.

Wu, B., J. Wang, and R. Zhang (2004), Effects of intraseasonal variations of the Arctic Oscillation on the Barents Sea, Polar Meteorolo. Glaciol., 18 , 82-95. 
WANG ET AL.: BERING ECOSYSTEM MODELING

Yao, T., C. L. Tang, and I. K. Peterson (2000), Modeling the seasonal variation of sea ice in the Labrador Sea with a coupled multi-category ice model and the Princeton Ocean Model, J. Geophys. Res., 105, $1153-1165$.

Zhang, J., R. Lindsay, M. Steele, and A. Schweiger (2008), What drove the dramatic retreat of arctic sea ice during summer 2007, Geophys. Res. Lett., 35, L11505, doi:10.1029/2008GL034005.
Zhang, J, R. Woodgate, and R. Moritz (2010a), Sea ice response to atmospheric and oceanic forcing in the Bering Sea, J. Phys. Oceanogr., 40 1729-1747, doi:http://dx.doi.org/10.1175/2010JPO4323.1.

Zhang, J., Y. H. Spitz, M. Steele, C. Ashjian, R. Campbell, L. Berline, and P. Matrai (2010b), Modeling the impact of declining sea ice on the Arctic marine planktonic ecosystem, J. Geophys. Res., 115, C10015, doi:10.1029/2009JC005387. 